\title{
Indirect climatic forcing of the Barents Sea capelin: a cohort effect
}

\author{
Dag Ø. Hjermann ${ }^{1}$, Nils Chr. Stenseth ${ }^{1,2, *}$, Geir Ottersen ${ }^{3,45}$ \\ ${ }^{1}$ Centre for Ecological and Evolutionary Synthesis (CEES), Department of Biology, University of Oslo, \\ PO Box 1050 Blindern, 0316 Oslo, Norway \\ ${ }^{2}$ Department of Coastal Zone Studies, Institute of Marine Research, Flødevigen Research Station, 4817 His, Norway \\ ${ }^{3}$ Institute of Marine Research, PO Box 1870 Nordnes, 5024 Bergen, Norway \\ ${ }^{4}$ Bjerknes Centre for Climate Research/GEOS, University of Bergen, Allégaten 55, 5007 Bergen, Norway \\ ${ }^{5}$ Present address: Centre for Ecological and Evolutionary Synthesis (CEES), Department of Biology, University of Oslo, \\ PO Box 1050 Blindern, 0316 Oslo, Norway
}

\begin{abstract}
Planktivorous capelin is a key species in the Barents Sea, being of great importance in the exploitation of plankton production in this subarctic region. However, in years with a successful reproduction of the Norwegian spring-spawning herring, large amounts of herring larvae drift into the Barents Sea, where they stay for 2 to $3 \mathrm{yr}$. The 1 to 2 yr old herring has a pronounced impact on capelin, eating large amounts of capelin larvae. The main fish predator of the Barents Sea, the ArctoNorwegian cod, also consumes large amounts of post-larval capelin. In this study, we show how temperature and the North Atlantic Oscillation (NAO) indirectly influence the population dynamics of capelin by influencing the reproduction of herring and cod. After 1980, when the herring spawning stock had recovered after its collapse in 1969, we found that temperature strongly negatively influences capelin cohorts 2 yr before spawning. Capelin cohorts which have spawned 2 yr after a warm year tend to experience high predation from both young herring as larvae and from 3 to 6 yr old cod during the rest of their life. Other analyses confirm that present sea temperatures or previous NAO conditions have strong positive effects on the abundance of 0 -group cod and herring. Thus, the climatic regime of the region ultimately determines the balance between capelin and herring, which in turn has pronounced consequences for the species composition and energy flow of the entire ecosystem.
\end{abstract}

KEY WORDS: Temperature - North Atlantic Oscillation · Cod · Herring • Time-series analysis · Indirect effects $\cdot$ Lagged effects

Resale or republication not permitted without written consent of the publisher

\section{INTRODUCTION}

\section{Climatic forcing in a macroecological context}

Marine biologists have long appreciated the profound influence of climate on ecological processes and patterns (Hjort 1914, Cushing 1982). A modelling study by Lekve et al. (2003) explicitly incorporated climate forcing when modelling the community dynamics of coastal benthic communities along the Norwegian Skagerrak coast. This work of Lekve et al. (2003) falls within the field of macroecology (see e.g. Brown \&
Maurer 1989) - a field which until now has been primarily exercised within the field of terrestrial ecology, and only recently been adopted for marine systems (e.g. Stevens 1996, Attrill et al. 2001, Belgrano et al. 2002, Li 2002, Smith \& Brown 2002). In this paper we provide by focusing on the Barents Sea, another example of a macroecological approach to a marine system.

Although climatic forcing certainly is appreciated as an important external process within terrestrial ecosystems (see e.g. Stenseth et al. 2002, Mysterud et al. 2003), terrestrial ecologists have focused less on ex- 
ternal forcing and much more on internal ecosystem processes (such as competition and trophic interactions). A marine approach to macroecology may therefore provide valuable conceptual feedback to the field of terrestrial macroecology. Furthermore, although macroecology deals with how species dynamically share the available food and space (e.g. Kendall et al. 1998), macroecological studies have tended to consider ecosystems as quite static in ecological time. Marine systems are highly dynamic, most conspicuously demonstrated by the dramatic changes in the abundance of pelagic fish (e.g. Klyashtorin 1998, Chavez et al. 2003). Such changes may be observed at several trophic levels as documented by Anderson \& Piatt (1999). Their findings were based on fish-scale records covering hundreds of years; hence, spanning a period long before fishing had any significant effect on the population dynamics of the species in question (see also Baumgartner et al. 1992, Alheit \& Hagen 1997, Corten 1999). Such decadal-scale fluctuations may be synchronized over large areas (e.g. across the Pacific) and are often assumed to be caused by large-scale climatic phenomena (Rodionov 1995, Schwartzlose et al. 1999, Chavez et al. 2003, but see Fréon et al. 2003).

Here, we focus on the effects of climate on the relationship between the 3 fish populations dominating the Barents Sea ecosystem: the Barents Sea capelin Mallotus villosus, the Norwegian spring-spawning herring Clupea harengus, and the Arcto-Norwegian cod Gadus morhua. Focusing on capelin, we explore how climate variation affects the dynamics of this population, effects which in turn might have marked effects on the structure and functioning of the entire ecosystem (Hamre 1994). Our analysis demonstrates that the observed effects of climate on capelin are, to a large extent, mediated through the reproduction of the coexisting cod and herring. The strength of a cod or herring cohort is, primarily, determined by the climatic conditions in the year of spawning (Hjort 1914). As a result, the climatic condition in a given year will have a lasting effect on the ecosystem in subsequent years, an effect we document here for capelin in the Barents Sea. Within the field of terrestrial ecology, this phenomenon is typically referred to as 'the cohort effect' (Stenseth et al. 2002). For instance, Mysterud et al. (2002) reported that the population density at the time of birth influenced the subsequent average body weight of adult red deer.

We adopt a macroecological approach in this paper. The classic macroecological approach has been to regard each species in a biota as one data point (see e.g. Brown 1999, Gaston \& Blackburn 1999). While this is applicable to some marine systems (e.g. benthic habitats, Lekve et al. 2003), it may not be a fruitful approach for pelagic fish biota, which usually are dominated by a few species. Therefore, we will adopt a slightly different approach and focus on how biotic and climatic processes affect capelin and the balance between capelin and herring. We do this by focusing on the analysis of a $29 \mathrm{yr}$ time series of capelin.

\section{Barents Sea ecological system: a capelin-focused synoptic account}

The Barents Sea covers an extensive geographic area $\left(1.4 \times 10^{6} \mathrm{~km}^{2}\right)$ north of Norway and northwestern Russia. The climate of this sub-polar shelf sea is closely linked to the influx of relatively warm Atlantic water. Fluctuations in this inflow drive large variation in temperature, as well as nutrients, both between years and on longer time-scales (Ottersen \& Stenseth 2001). There is also a large, but varying, influx of the calanoid copepod Calanus finmarchicus each spring from its main overwintering area in the Norwegian Sea (Slagstad \& Tande 1996, Sundby 2000). The fish community is dominated by a few very abundant species, resulting in strong interspecific interactions (Hamre 1994, Figs. 1 $\& 2)$. The capelin, the dominant planktivore in the Barents Sea over the last 30 yr (Gjøsæter et al. 2002), follows the productive ice-melt zone in spring and summer and migrates back south to winter (Fig. 1). In January, maturing 2 to 4 yr old capelin start to separate from the rest of the population and migrate to the coasts of Norway and Russia to spawn. Most of them spawn only once (Gjøsæter 1998). By biomass, the capelin is the most abundant fish of the Barents Sea (up to $6 \times 10^{6}$ tonnes) - of which as much as $2.9 \times 10^{6}$ tonnes has been harvested (in 1977) (Gjøsæter 1998, Ushakov \& Prozorkevich 2002).

Another pelagic plankton-feeder, the Norwegian spring-spawning herring, lives primarily in the Norwegian Sea but uses the Barents Sea as a nursing area. After spawning on the western coast of Norway, their offspring drift to the Barents Sea, where they live until they migrate to the Norwegian Sea, typically at Age 3 (Hamre 1994). Herring eat capelin larvae (cf. Fig. 1), and the presence of substantial amounts of 1 to $2 \mathrm{yr}$ old herring (more than $0.75 \times 10^{6}$ million tonnes) is associated with very low capelin reproduction in most years, close to zero reproduction during some years (Gjøsæter \& Bogstad 1998, Huse \& Toresen 2000). Herring was practically absent from the Barents Sea after the collapse of the herring stock in 1969, until a successful reproduction in 1983 (Fig. 3c). Since the recovery of the herring stock, the capelin stock has collapsed twice, being reduced by approximately $97 \%$ each time (Gjøsæter 1998, Fig. 3a,b).

The other main predator of capelin is cod, mainly 3 to $6 \mathrm{yr}$ of age, that may consume up to $4 \times 10^{6}$ tonnes of capelin (1 yr and up) annually (Dolgov 2002). Capelin 


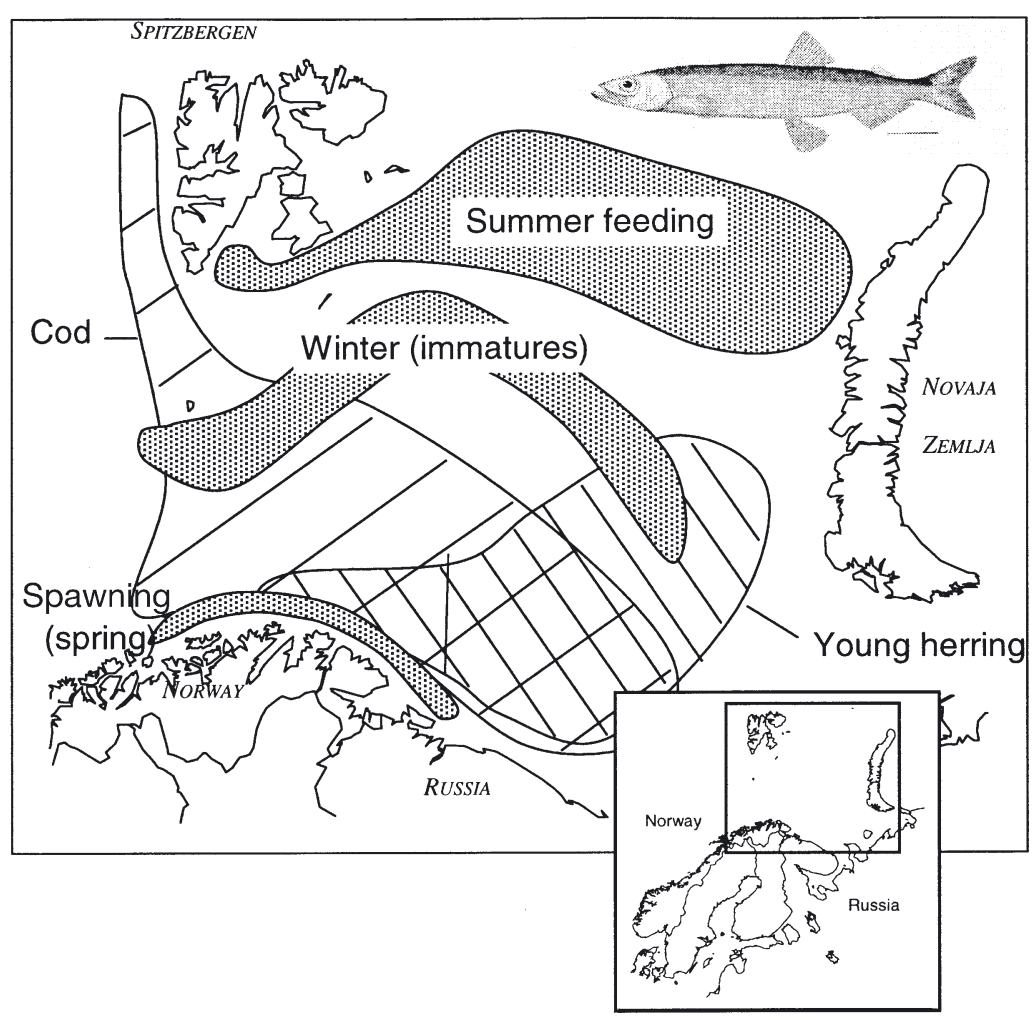

Fig. 1. Mallotus villosus and its predators. The study area, showing the summer, winter and spring spawning areas of capelin (grey), the winter area of immature cod Gadus morhua (hatching up to the left) and the areas of 1 to 2 yr old herring Clupea harengus (hatching up to the right). All areas are approximate and vary from year to year

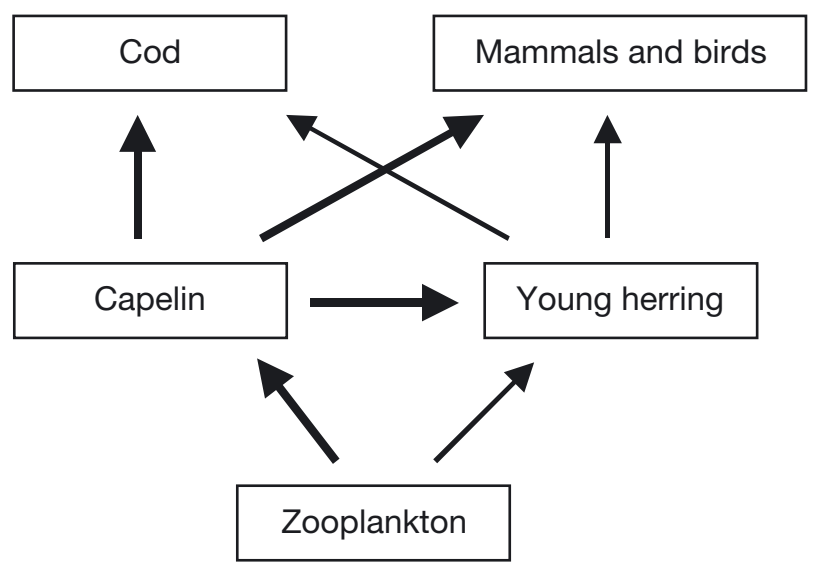

Fig. 2. Main components of the food web, showing the relationship between the focal species of this study: the capelin Mallotus villosus, the Arcto-Norwegian cod Gadus morhua, and the Norwegian spring-spawning herring Clupea harengus. Line thickness indicates roughly the importance of the pathways Fig. 3d). are only weakly influenced directly by climate (the somatic growth is to some degree influenced by temperature, but is affected by density to a much stronger degree; Gjøsæter 1998). In contrast, the recruitment of both herring and cod (Fig. 3c) is strongly associated with warm years. Thus, in warm years, herring and cod tend to have good reproduction and produce strong year-classes (Ottersen et al. 1994, Ottersen \& Loeng 2000, Toresen \& Østvedt 2000, Ottersen \& Stenseth 2001, Pope et al. 2001). One and 2 yr later, the strong herring year-class will exert a high predation pressure on capelin larvae, while 3 to 6 yr later, the strong cod year-classes will exert a high predation pressure on capelin of Ages 1 to 4 .

Therefore, if climate mainly affects capelin indirectly through its predators, we expect that capelin spawned 1 and 2 yr after a warm year suffer most heavily from predation by both herring and cod (Fig. 4). If cod predation is important, the year-class 2 yr after a warm year will probably suffer most. The negative influence of temperature on capelin population growth rate with a 1 or 2 yr time lag forms the a priori hypothesis of this paper.

\section{MATERIALS AND METHODS}

Climatic data. Annual mean sea temperatures from the Russian Kola meridian transect $\left(33^{\circ} 30^{\prime} \mathrm{E}, 70^{\circ} 30^{\prime} \mathrm{N}\right.$ to $72^{\circ} 30^{\prime} \mathrm{N}$ ) were used (Bochkov 1982, Tereshchenko 1996); the most recent temperatures have been provided by the Polar Institute of Marine Fishery and Oceanography (PINRO, Murmansk). Monthly average values were calculated by averaging along the transect and from 0 to $200 \mathrm{~m}$ depth vertically (Fig. 3d). In addition, we used the winter index of the North Atlantic Oscillation (NAO), a measure of the distribution of atmospheric pressure in the North Atlantic (Hurrell et al. 2003, Stenseth et al. 2003). We have used the index based on the difference of normalized sea level pressure between Lisbon, Portugal and Stykkisholmur/ Reykjavik, Iceland from December to March (available at www.cgd.ucar.edu/ jhurrell/ nao.html). Throughout the last decades, the NAO has been strongly correlated to Barents Sea temperature (Ottersen et al. 2001, 

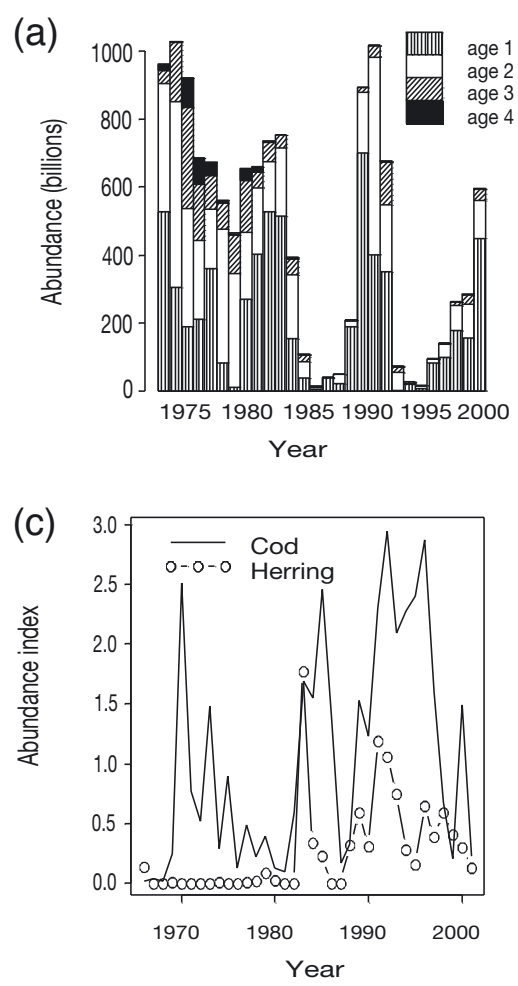

where $M_{i, t}$ is the number of maturing capelin of age $i$ in year $t$. The proportion of maturing capelin was estimated on the basis of average length, assuming a logistic relationship between individual length $(L)$ and maturation, $f$ : $f=1 /\left(1+\mathrm{e}^{2.4\left(L_{50}-L\right)}\right)$, where $L_{50}$ was 13.9 $\mathrm{cm}$ for 3 and $4 \mathrm{yr}$ olds and $14.2 \mathrm{~cm}$ for 2 yr olds (Gjøsæter 1998). Individual length was assumed to be normally distributed within each age group, with a standard deviation equal to that observed during the period covered by the time-series data $(1.33,1.24$ and 1.01 for 2,3 and 4 yr olds, respectively).

Since $r$ is strongly dependent on spawner abundance (Fig. 3b), we controlled for spawner abundance in the analyses of $r$ (i.e. we included $\left[M_{2, t}+\right.$ $\left.M_{3, t}+M_{4, t}\right]$ as a factor in the analyses).

Cod and herring 0-group abundance. We used abundance indices of pelagic 0-group (ca. 5 mo old) fish from 1966 to 1999, available from ICES $(2002 a, b)$ and originating from the International 0-group Survey in August and September each year (a cooperation between IMR and PINRO). The fish were sampled at several depths at a number of stations, using a small mesh midwater trawl (Randa 1982, 1984). We have used the socalled log-index, which is an index

Capelin population growth. We estimated population growth based on estimates from the joint Russian/Norwegian acoustic survey of pelagic fish from 1973 to 2000. This survey is carried out annually in September to October as a joint effort between the Institute of Marine Research (IMR), Bergen and PINRO. We used the estimates of capelin abundance for each age, from 1 to $4 \mathrm{yr}$, as reported in the survey report (available at www.imr.no), and data of mean length obtained from IMR. We estimated the population growth rate based on the change in the number of maturing capelin (fish that will mature and attempt spawning the following spring; see below) over one generation. We defined the net population growth rate $(r)$ as $\log \left(R_{0}\right) / T$, where $R_{0}$ is the mean number of maturing fish produced by each maturing fish in the previous generation and $T$ is the average generation length (measured as the mean age at spawning):

$$
\begin{gathered}
R_{0}=\left(M_{2, t+3}+M_{3, t+4}+M_{4, t+5}\right) /\left(M_{2, t}+M_{3, t}+M_{4, t}\right) \\
T=\left(3 M_{2, t+3}+4 M_{3, t+4}+5 M_{4, t+5}\right) /\left(M_{2, t}+M_{3, t}+M_{4, t}\right)
\end{gathered}
$$

based on back-transformed logarithmic means (Randa 1982, 1984). In some of the reported analyses we also utilized the spawning stock biomass (SSB) of herring and cod, retrieved from ICES reports (ICES $2002 a, b)$.

Statistical analyses. We analysed details of whether the per-generation growth rate $(r)$ of capelin could be predicted from temperature 0 to 2 yr before spawning of the parental generation (hereafter denoted lag $=0$ to 2 ), and NAO 0 to 4 yr before spawning. We also analyzed the relationship between capelin $r$ and the 0-group abundance of cod and herring 0 to 3 yr before capelin spawning. Finally, we performed a similar analysis for the relationship between climate and the 0 -group abundance of cod and herring. We used general additive models (GAM) with a loess smoother $($ span $=0.8)$ to allow for non-linear effects; the 'best' models were chosen on the basis of stepwise selection using, unless otherwise stated, Mallow's $C_{\mathrm{p}}$ (equivalent to the Akaike Information Criterium, AIC) as the optimization criterion. 


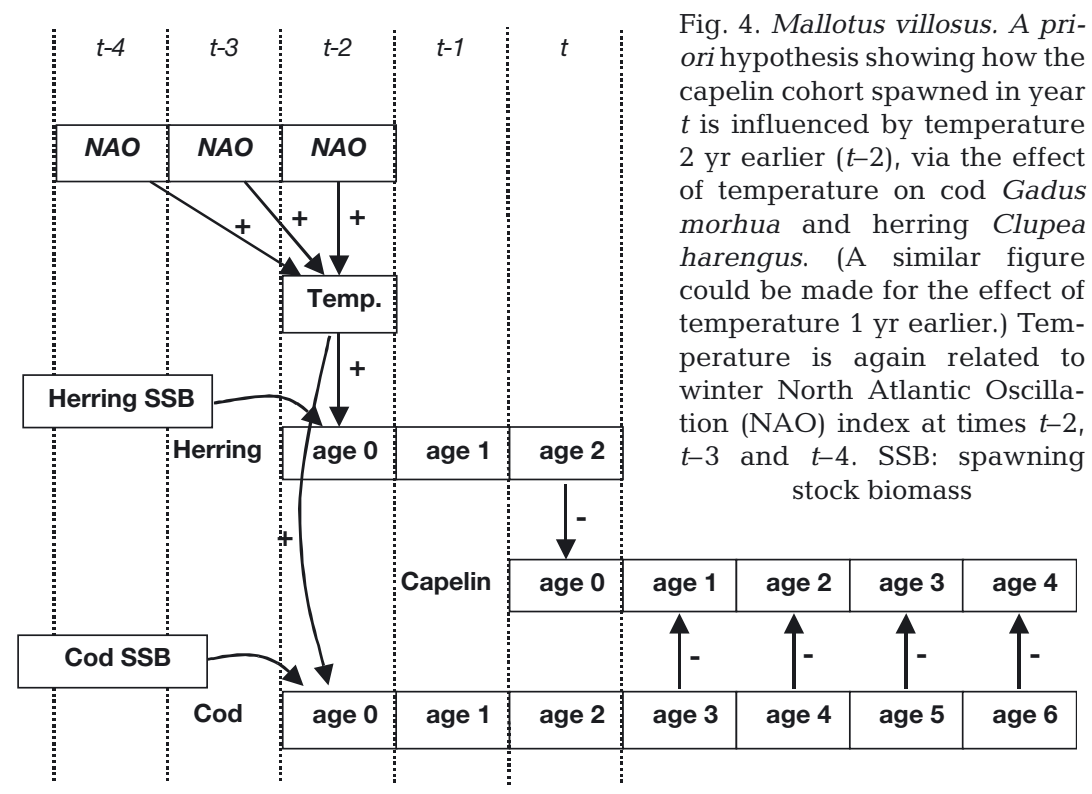

models not corrected for cohort abundance. We found a negative correlation with NAO 2 yr before capelin spawning (Table 2a). However, if we exclude the first 7 yr (1974 to 1980 spawners; i.e. the generations little affected by the return of herring in 1983), NAO with lag-2 loses some of its explanatory power $(F=4.41$, $\mathrm{p}=0.056)$. For this set of years, lag- 2 temperature is seen to be a better explanatory factor (Table 2b). However, if we add the abundance of herring as an explanatory factor (using all years in the analysis), we found a strong and additive negative effect of the abundance of 0 group herring 1 and 2 yr before spawning (Table 2c). This model explained almost all variation in $r$ (Fig. 5), but Mallow's $C_{\mathrm{p}}$ was even further improved by adding temperature and NAO (Table 2e). If herring was excluded as an

Table 1. Correlations (Pearson correlation coefficient) between the North Atlantic Oscillation (NAO) winter index and mean 0 to $200 \mathrm{~m}$ Kola temperature, during the period 1965 to 2001. Correlations were corrected for autocorrelation by adjusting the sample size by the factor $\left(1-\alpha_{1} \alpha_{2}\right)\left(1+\alpha_{1} \alpha_{2}\right)$, where $\alpha_{1}$ and $\alpha_{2}$ are each variable's lag-1 autocorrelation coefficient (Priestley 1981, Lekve et al. 1999). ${ }^{*} 0.01 \leq \mathrm{p} \leq 0.05$; ${ }^{* *} 0.001 \leq \mathrm{p} \leq 0.01 ; t$ : year

\begin{tabular}{|lll|}
\hline & $\mathrm{NAO}_{t}$ & Temperature \\
\hline $\mathrm{NAO}_{t}$ & - & $0.52^{* *}$ \\
$\mathrm{NAO}_{t-1}$ & $0.34^{*}$ & $0.50^{* *}$ \\
$\mathrm{NAO}_{t-2}$ & 0.13 & $0.42^{*}$ \\
Temperature $_{t}$ & $0.52^{* *}$ & - \\
Temperature $_{t-1}$ & 0.07 & $0.48^{* *}$ \\
Temperature $_{t-2}$ & 0.09 & 0.18 \\
\hline
\end{tabular}

\section{RESULTS}

\section{Correlations between climate indicators}

As shown in Table 1, the annual mean temperature at 0 to $200 \mathrm{~m}$ depth in the Kola section was both highly autocorrelated in time, and related to the NAO winter index of the last $3 \mathrm{yr}$. The NAO index is autocorrelated to a smaller degree, and is not related to previous temperatures.

\section{Correlations between climate and capelin population growth (without herring and/or cod)}

The relationship between cohort abundance and $r$ is strong (Fig. 3b); hence, we do not report results from explanatory factor, cod with a 1 yr time lag provided a quite high explanatory value as well (Table $2 \mathrm{~d}$ ).

\section{Correlations between climate and the abundance of 0 -group cod and herring}

For cod, we found that if we did not control for cod SSB, the best model for 0-group abundance consisted of a linear, positive effect of current temperature as well as a non-linear effect of NAO 2 yr earlier (Table 3a). The amount of 0-group cod was lowest when the NAO index was intermediate 2 yr earlier (Fig. 6a). If we did control for $\mathrm{SSB}$, however, the effect of NAO with a 2 yr lag was positive, and linearly related to cod abundance (Table $3 \mathrm{~b}$ ).

The best model for herring abundance (without her-

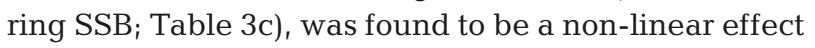
of NAO 2 yr earlier, similar to the model found for cod (Fig. 6c). In addition, we found a lagged non-linear effect of temperature $2 \mathrm{yr}$ earlier (abundance declining for temperatures below $\sim 3.4^{\circ} \mathrm{C}_{i}$ Fig. 6 b), and a linearly positive effect of the current NAO index. By controlling for herring SSB, we found a linearly positive effect of NAO 2 yr earlier, just as was found for cod (Table 3d). However, $\mathrm{R}^{2}$ was low for this model.

\section{DISCUSSION}

\section{Indirect effects of climate on capelin}

Our analysis shows that reproduction and survival of capelin is indirectly, but strongly, linked to climate, as 
Table 2. Mallotus villosus. Optimal statistical models explaining per-generation capelin population growth $(r)$. Lags are relative to the spawning year of the parental stock. Analysis covers parental spawning years 1974 to 1996 (1981 to 1996 in b). Intercept estimates are not shown. NAO: North Atlantic Oscillation

\begin{tabular}{|c|c|c|c|}
\hline & Estimate & $F$ & $\mathrm{p}$ \\
\hline \multicolumn{4}{|c|}{ (a) Best model without cod and herring 0 -group abundance $\left(R^{2}=0.63\right)$} \\
\hline $\log ($ capelin spawner abundance) & -0.33 & 27.88 & $<0.0001$ \\
\hline NAO index $(\operatorname{lag}=2)$ & -0.33 & 7.87 & 0.029 \\
\hline \multicolumn{4}{|c|}{ (b) As in (a), but using only 1981 to 1996 data $\left(R^{2}=0.82\right)$} \\
\hline $\log ($ capelin spawner abundance) & -0.45 & 59.29 & $<0.0001$ \\
\hline Sea temperature $(\operatorname{lag}=2)$ & -0.43 & 6.18 & 0.027 \\
\hline \multicolumn{4}{|c|}{ (c) Best model without cod 0 -group abundance and climate $\left(R^{2}=0.84\right)$} \\
\hline log(capelin spawner abundance) & -0.33 & 61.94 & $<0.0001$ \\
\hline Abundance herring 0-group (lag $=1$ ) & -0.51 & 13.47 & 0.002 \\
\hline Abundance herring 0-group $(\operatorname{lag}=2)$ & -0.49 & 12.18 & 0.002 \\
\hline \multicolumn{4}{|c|}{ (d) Best model without herring 0-group abundance and climate $\left(R^{2}=0.70\right)$} \\
\hline $\log ($ capelin spawner abundance) & -0.37 & -6.53 & $<0.0001$ \\
\hline Abundance cod 0-group (lag = 1) & -0.32 & -3.44 & $<0.003$ \\
\hline \multicolumn{4}{|l|}{ (e) Best overall model $\left(R^{2}=0.88\right)$} \\
\hline $\log ($ capelin spawner abundance) & -0.34 & -8.72 & $<0.0001$ \\
\hline Abundance herring 0-group $(\operatorname{lag}=1)$ & -0.65 & -4.37 & $<0.001$ \\
\hline Abundance herring 0-group (lag $=2$ ) & -0.44 & -3.10 & 0.0065 \\
\hline NAO index $(\operatorname{lag}=2)$ & -0.076 & -1.85 & 0.082 \\
\hline Sea temperature $(\operatorname{lag}=1)$ & 0.35 & 2.10 & 0.051 \\
\hline
\end{tabular}

Temp $_{t}$ Table 1), this finding links high capelin population growth to generally low temperatures (both in the year of spawning as well as in the 2 preceding years). However, the generally high level of capelin in the 1970s compared to the 1980s and 1990s influences this result. The late 1970 s was a generally cold, low-NAO period, but also the SSB of herring was extremely low after the 1969 collapse. During 1981 to 1996, when the herring SSB became sufficiently large to produce rich yearclasses of offspring, the best predictior for capelin population growth was Temp $_{t-2}$ (Table 2b), just as expected from Fig. 4. The hypothesized relationship of Fig. 4 is supported by 3 additional analyses: First, herring and cod 0-group abundance were each good predictors of capelin population growth (Table 2c,d). Second, including climate in addition to herring increases the explanation power by only $4 \%\left(\mathrm{R}^{2}=\right.$ 0.84 and 0.88 , respectively, Table $2 \mathrm{c}, \mathrm{e}$ ), indicating that direct effects of climate appear to be, at best, quite weak. Third, best models for cod and herring

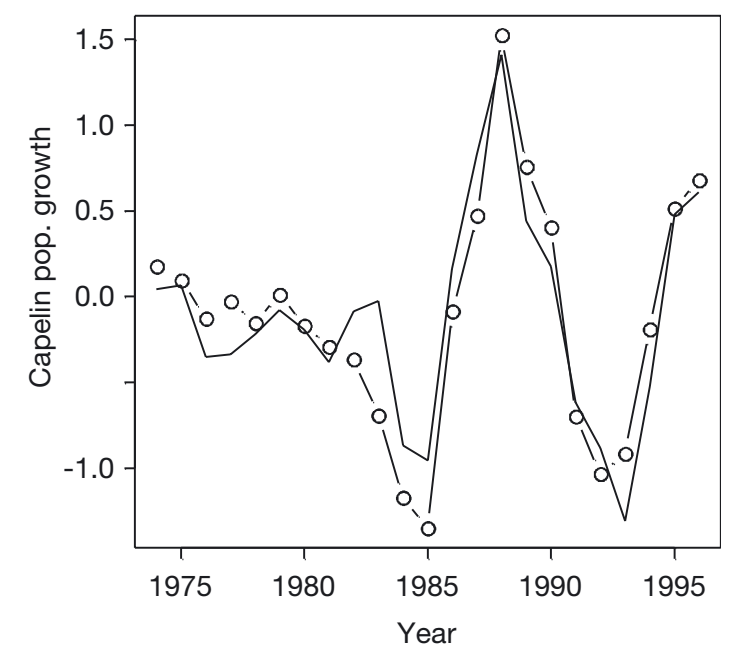

Fig. 5. Mallotus villosus. Predictions of population growth rate, in a linear model with abundance of capelin spawners as well as the abundances of 0 -group herring 1 and 2 yr before spawning $\left(-0-\right.$ observed $_{i}-=$ predicted $)$

hypothesized in Fig. 4. For the entire period from 1973 to 1996 , capelin population dynamics were linked to the NAO 2 yr before spawning, hereafter denoted as $\mathrm{NAO}_{t-2}$ (Table 2a). Since $\mathrm{NAO}_{t-2}$ is related to temperature in Year $t-2, t-1$ and $t\left(\mathrm{Temp}_{t-2}, \mathrm{Temp}_{t-1}\right.$ and 0-group abundance confirm the strong effect of NAO with a 2 yr time lag (Table 3d). Also Hamre (2000), who explored a model with temperature, cod, capelin and herring, found that the temperature-herring-capelin link was the strongest dynamic element of his model.

The cod cohort spawned 2 yr before capelin would be 3 to $6 \mathrm{yr}$ old when the capelin are 1 to $4 \mathrm{yr}$ old (Fig. 4). Indeed, most capelin predated by cod are in fact eaten by these age groups (Dolgov 2002), which could be part of the explanation for the effect of Temp $_{t-2}$ (Table 2b). Excluding herring as an explanatory factor, we find the best explanatory factor to be cod 0-group abundance $1 \mathrm{yr}$, not $2 \mathrm{yr}$, before capelin spawning. Since they are highly correlated $(\mathrm{R}=0.66$, $\mathrm{p}<0.001$ ), it is, however, hard to discriminate between the effect of lag-1 and lag-2 cod abundance. According to the hypothesis outlined in Fig. 4, we would expect the best overall model for capelin growth to be a model with effects of herring and cod, and no effects of climate. This was not the case (Table 2e). Again, the effect of cod may be swamped by the effect of lag-1 and lag- 2 herring abundance, since $54 \%$ of lag- 1 cod abundance is explained by lag-1 and lag- 2 herring abundance. In fact, herring abundance is much more closely correlated with the cod abundance $(\mathrm{R}=0.60$, $\mathrm{p}<0.01)$ than with herring abundance $(\mathrm{R}=0.32, \mathrm{p}=$ 0.13 ) the year after. The 0 -group survey has not been 
Table 3. Gadus morhua and Clupea harengus. Optimal statistical models explaining influences on the abundance of 0-group cod $(a, b)$ and herring $(c, d)$. Years refer to the spawning year of the parental stock. Intercept estimates are not shown. SSB: spawning stock biomass

\begin{tabular}{|c|c|c|c|c|}
\hline & Estimate & $F$ & $\mathrm{p}$ & $\mathrm{p}$ (linearity) \\
\hline \multicolumn{5}{|c|}{ (a) Cod 0-group abundance - without $\operatorname{cod} \operatorname{SSB}\left(\mathrm{R}^{2}=0.53\right)$} \\
\hline Sea temperature $(\operatorname{lag}=0)$ & 0.67 & 6.98 & 0.013 & \\
\hline NAO index $(\operatorname{lag}=2)$ & Non-linear & 7.87 & $<0.001$ & 0.015 \\
\hline \multicolumn{5}{|c|}{ (b) Cod 0-group abundance - with cod SSB $\left(R^{2}=0.55\right)$} \\
\hline $\log (\operatorname{cod} \mathrm{SSB})$ & 0.88 & 15.52 & $<0.001$ & \\
\hline NAO index $(\operatorname{lag}=2)$ & 0.14 & 6.60 & 0.014 & \\
\hline \multicolumn{5}{|c|}{ (c) Herring 0-group abundance - without herring $\operatorname{SSB}\left(\mathrm{R}^{2}=0.51\right)$} \\
\hline NAO index $(\operatorname{lag}=0)$ & 0.063 & 6.46 & 0.017 & \\
\hline Sea temperature $(\mathrm{lag}=2)$ & Non-linear & 3.10 & 0.042 & 0.078 \\
\hline NAO index $(\operatorname{lag}=2)$ & Non-linear & 7.06 & 0.002 & 0.007 \\
\hline \multicolumn{5}{|c|}{ (d) Herring 0-group abundance - with herring $\operatorname{SSB}\left(\mathrm{R}^{2}=0.36\right)$} \\
\hline $\log ($ herring SSB) & 0.078 & 8.07 & 0.007 & \\
\hline NAO index $(\operatorname{lag}=2)$ & 0.32 & 7.18 & 0.011 & \\
\hline
\end{tabular}

destratification at the time of emergence (Frank \& Carscadden 1989). While researchers in the NW Atlantic have found capelin recruitment to be affected by wind conditions during a very short critical period (e.g. $10 \mathrm{~d}$ after median hatching; Leggett et al. 1984), we (and other researchers) have looked for possible effects only among much more broad-scaled environmental variables. Therefore, effects of wind or other environmental variables during a short critical period could be important in the Barents Sea capelin as well. However, not much residual variation in capelin success remains to be explained after taking predator abundance and broad-scaled climate into account $(<20 \%$; Table 2$)$. Thus, our analyses indicate not merely that we have found no evidence of direct environmental effects, but also that there is

found to give very good estimates for cod, since part of the 0-group cod already may have moved from a pelagic to a demersal habitat in this part of the year (Helle et al. 2000). However, the results were similar if we used Virtual Population Analysis (VPA) estimates of Age 3 cod. The good recruitment of capelin in the early 1970 s during a high cod stock indicates that a high capelin stock is quite resilient to cod predation.

While climate clearly influences the spawning migrations and spawing locations of capelin (Ozhigin \& Luka 1985, Tjelmeland 1987), this study shows no evidence for strong direct effects of climate on capelin dynamics. This confirms earlier findings that Barents Sea capelin is much more affected by predation (and harvest) than by direct climatic effects or climatic effects acting through plankton (Bogstad \& Gjøsæter 1994, Gjøsæter 1998, Gjøsæter \& Bogstad 1998). The same is true for the Icelandic stock (Vilhjalmsson 2002). In sharp contrast, year-class strength of the capelin stocks of the NW Atlantic is strongly linked with climate through direct effects (Leggett et al. 1984, Carscadden et al. 2000, 2001). For the beach-spawning stocks in this area, larval emergence is strongly linked to periods of onshore winds and warm, food-rich, predator-poor surface waters. Strong year-classes are associated with a high frequency of onshore winds during the critical period immediately after hatching. One could attribute the lack of effects in the Barents Sea and Icelandic stocks to the fact that they spawn on the bottom near the coast, in contrast to 4 of the $5 \mathrm{NW}$ Atlantic stocks. However, the bottom-spawning stock in the NW Atlantic also appears to be positively affected by wind-forcing events, possibly linked to not much room left for such effects. An interesting issue for future research is why direct environmental effects dominate the NW Atlantic capelin stocks, while predation dominates the Barents Sea stock.

In the analyses of climatic effects on the 0-group abundance of cod and herring, we found quite similar results regarding $\mathrm{NAO}_{t-2}$. If we did not control for SSB (but did control for current temperature/NAO), $\mathrm{NAO}_{t-2}$ had a strongly non-linear effect in both cases, with intermediate NAO resulting in low 0-group abundance (Fig. 6a,c). Such non-linear responses to NAO have been reported in terrestrial systems (see Mysterud et al. 2003 for a review); however, we find it outside the scope of this study to pursue the background of this result. In the analyses where the effect of SSB is taken into account, it is interesting to note that $\mathrm{NAO}_{t-2}$ (being related to $\mathrm{Temp}_{t-2}$, Temp $\mathrm{P}_{t-1}$ and $\mathrm{Temp}_{t}$ ) in both cases had a more strongly positive effect than Temp ${ }_{t}$. Thus, the present temperature condition does not appear to be the best predictor of cod and herring reproduction.

\section{Significance of capelin in the Barents Sea system}

When juvenile herring replaces capelin during capelin collapses, the entire ecosystem is changed. First, capelin is the only species able to effectively exploit the rich plankton bloom along the ice edge (Gjøsæeter \& Loeng 1987, Hassel et al. 1991, Gjøsæter et al. 2002). The herring does not go as far north as the capelin. The plankton-feeding polar cod Boreogadus saida tolerates cold waters, but forages further down in the water column and not as effectively as the capelin (Hamre 1994). 

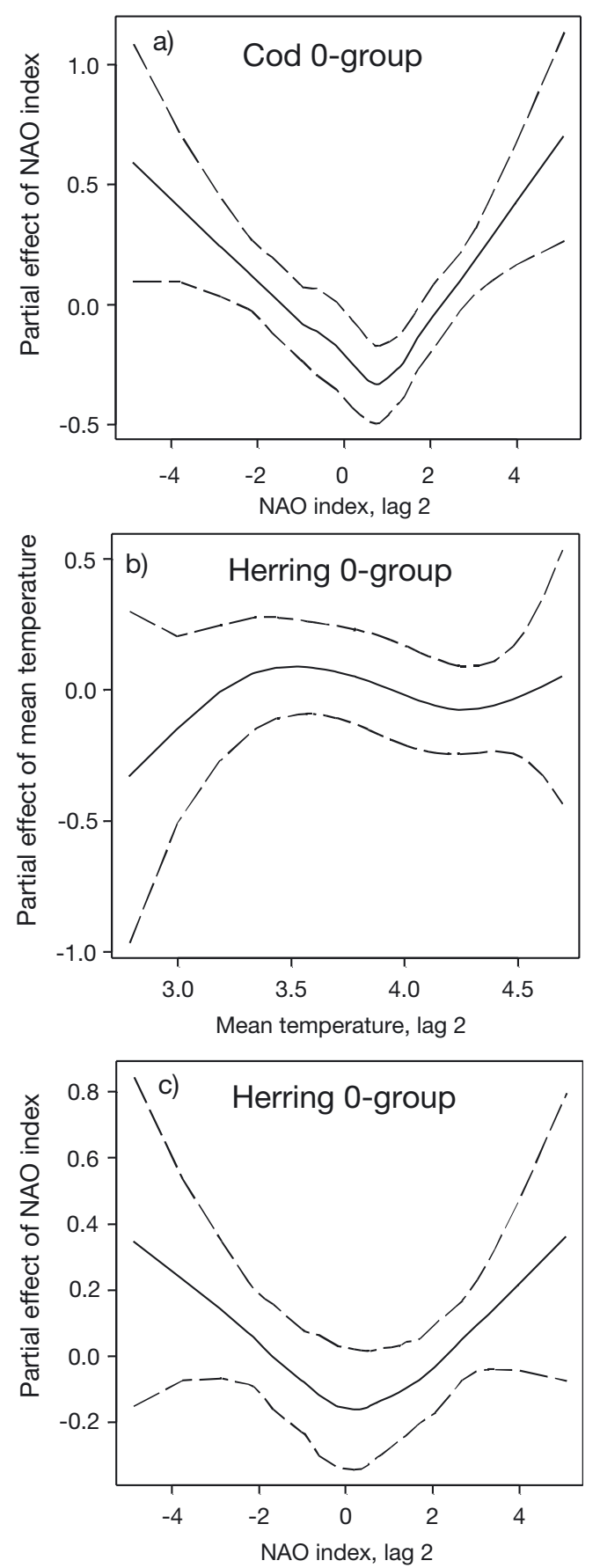

Fig. 6. Non-linear effects. (a) Gadus morhua. Partial effect of North Atlantic Oscillation (NAO) in the model of cod 0-group abundance without spawning stock biomass (SSB). (b), (c) Clupea harengus. Partial effect of temperature (b) and NAO (c) in the model of herring 0-group abundance without SSB

Second, the capelin effectively transports a substantial amount of energy from the remote central and northern Barents Sea to the coastal areas, where it becomes easily available for piscivorous fish, seabirds, mammals and fishery activities restricted to the southern parts of the Barents Sea. In contrast, much of the biomass accumulated by the herring is moved out of the Barents Sea when the $3 \mathrm{yr}$ old herring returns to the Norwegian Sea. Third, several predatory species (e.g. cod) prefer capelin to herring, and other species (such as the common guillemot Uria aalge) appear to specialize on capelin. Finally, quite a low biomass of juvenile herring is able to block the reproduction of capelin, replacing a large capelin biomass with a small herring biomass. Altogether, the lagged effect of a warm period leads to large changes in the ecosystem at all levels, and a generally poorer transfer of energy from low to high trophic levels (von Quillfeldt et al. 2002).

\section{CONCLUSION}

The present analysis suggests that the survival of capelin in the Barents Sea depends on periods with poor recruitment of cod and herring (i.e. cold periods). In turn, this affects the whole ecosystem significantly. If the temperature of the Barents Sea varies in a periodic fashion, suggested by some authors (see discussion in Ottersen et al. 2000), this may lead to cycles in the ecosystem state. This was indeed found by Hamre (2000) when simulating the fish stocks with temperature cycles of 8 to $9 \mathrm{yr}$ periods. In addition, he found the cyclic tendency to be exaggerated by a lagged negative effect on cod during capelin collapses.

The heat content of the Northern Atlantic has experienced an increasing trend over the last few decades (Barnett et al. 2001). According to available climate scenarios, this tendency is expected to continue (Vinnikov et al. 1999). Thus, the predation pressure on capelin from herring and cod may become permanently very high. Also, the southern ice limit will probably move northwards. One could imagine that the capelin simply would move its summer distribution northwards, too. However, that would lead to an increasing distance to the spawning grounds, if the spawning location is not radically changed. Also, the same 'ice edge effect' may not be seen when the ice moves further north, for instance, because of the larger bottom depths towards the northern Barents Sea. Altogether, in a global warming perspective, the capelin faces an uncertain future, at least its position as a major player in the Barents Sea ecosystem is uncertain.

In this investigation we have demonstrated that indirect climatic effects may have a profound impact on key species in the ecosystem. These effects act through what properly should be called a cohort effect, leading to a time lag between changes in climate and effects on the capelin. The changes in capelin abundance can in turn lead to new, lagged effects; for instance, the abundance of capelin affects the per capita egg production 
of cod (Marshall et al. 1999). Hence, climate change might lead to large changes in the ecosystem in 2 different ways. First, an increase in the average temperature resulting from global warming might lead to a quite dramatic decrease in the average capelin abundance, which undoubtedly leads to substantial changes in the energy flow, and species composition, of the ecosystem. Second, any change in the temporal pattern of temperature, e.g. how many years the warm periods typically last, may lead to a change in the dynamics of the ecosystem. The end product of such changed dynamics is much more difficult to predict. Therefore, as a result of the interplay between climate and the internal processes, modest changes in climate might ultimately lead to a very different ecosystem. In the light of the predicted future changes in climate, understanding this interplay is a challenge of great academic and practical importance.

Acknowledgements. We thank PINRO (Murmansk) for most kindly providing temperature data from the Kola transect as well as providing, together with the Institute of Marine Research, Bergen, the abundance and length data on the capelin. We also thank J. Hamre, H. Gjøsæter, K. Lekve and 2 anonymous reviewers for improving this paper through their input. This work was supported by the Research Council of Norway (D.Ø.H. through the EcoClim-project of the University of Oslo, and G.O. through the Strategic Institute Program 134278/130 between the University of Oslo and the Institute of Marine Research). The work was carried out within the framework of the international GLOBEC program.

\section{LITERATURE CITED}

Alheit J, Hagen E (1997) Long-term climate forcing of European herring and sardine populations. Fish Oceanogr 6: 130-139

Anderson PJ, Piatt JF (1999) Community reorganization in the Gulf of Alaska following ocean climate regime shift. Mar Ecol Prog Ser 189:117-123

Attrill MJ, Stafford R, Rowden AA (2001) Latitudinal diversity patterns in estuarine tidal flats: indications of a global cline. Ecography 24:318-324

Barnett TP, Pierce DW, Schnur R (2001) Detection of anthropogenic climate change in the world's oceans. Science 292:270-274

Baumgartner TR, Soutar A, Ferreirabartrina V (1992) Reconstruction of the history of Pacific sardine and northern anchovy populations over the past 2 millennia from sediments of the Santa-Barbara Basin, California. Calif Coop Ocean Fish Investig Rep 33:24-40

Belgrano A, Allen AP, Enquist BJ, Gillooly JF (2002) Allometric scaling of maximum population density: a common rule for marine phytoplankton and terrestrial plants. Ecol Lett 5:611-613

Bochkov YA (1982) Water temperature in the 0-200 m layer in the Kola-Meridian in the Barents Sea, 1900-1981. Sb Nauchn Tr Polar Inst Mar Fish Oceanogr Murmansk 46: 113-122

Bogstad B, Gjøsæter H (1994) A method for estimating the consumption of capelin by cod in the Barents Sea. ICES J Mar Sci 51:273-280
Brown JH (1999) Macroecology: progress and prospect. Oikos 87:3-14

Brown JH, Maurer BA (1989) Macroecology: the division of food and space among species on continents. Science 243: $1145-1150$

Carscadden JE, Frank KT, Leggett WC (2000) Evaluation of an environment-recruitment model for capelin (Mallotus villosus). ICES J Mar Sci 57:412-418

Carscadden JE, Frank KT, Leggett WC (2001) Ecosystem changes and the effects on capelin (Mallotus villosus), a major forage species. Can J Fish Aquat Sci 58:73-85

Chavez FP, Ryan J, Lluch-Cota SE, Niquen M (2003) From anchovies to sardines and back: multidecadal change in the Pacific Ocean. Science 299:217-221

Corten A (1999) A proposed mechanism for the Bohuslan herring periods. ICES J Mar Sci 56:207-220

Cushing DH (1982) Climate and fisheries. Academic Press, London

Dolgov AV (2002) The role of capelin (Mallotus villosus) in the foodweb of the Barents Sea. ICES J Mar Sci 59:1034-1045

Frank KT, Carscadden JE (1989) Factors affecting recruitment variability of capelin (Mallotus villosus) in the Northwest Atlantic. J Conseil 45:146-164

Fréon P, Mullon C, Voisoin B (2003) Investigating remote synchronous patterns in fisheries. Fish Oceanogr 12:443-457

Gaston KJ, Blackburn TM (1999) A critique for macroecology. Oikos 84:353-368

Gjøsæter H (1998) The population biology and exploitation of capelin (Mallotus villosus) in the Barents Sea. Sarsia 83: 453-496

Gjøsæter H, Bogstad B (1998) Effects of the presence of herring (Clupea harengus) on the stock-recruitment relationship of Barents Sea capelin (Mallotus villosus). Fish Res 38:57-71

Gjøsæter H, Loeng H (1987) Growth of the Barents Sea capelin, Mallotus villosus, in relation to climate. Environ Biol Fish 20:293-300

Gjøsæter H, Dalpadado P, Hassel A (2002) Growth of Barents Sea capelin (Mallotus villosus) in relation to zooplankton abundance. ICES J Mar Sci 59:959-967

Hamre J (1994) Biodiversity and exploitation of the main fish stocks in the Norwegian-Barents Sea ecosystem. Biodivers Conserv 3:473-492

Hamre J (2000) Capelin and herring as key species for the yield of north-east Arctic cod. Results from multispecies model runs. Sci Mar 67 (Suppl 1):315-323

Hassel A, Skjoldal HR, Gjøsæter H, Loeng H, Omli L (1991) Impact of grazing from capelin (Mallotus villosus) on zooplankton-a case-study in the northern Barents Sea in August 1985. Polar Res 10:371-388

Helle K, Bogstad J, Marshall CT, Michalsen K, Ottersen G, Pennington M (2000) An evaluation of recruitment indices for Arcto-Norwegian cod (Gadus morhua L.). Fish Res 48: $55-67$

Hjort J (1914) Fluctuations in the great fisheries of northern Europe viewed in the light of biological research. Rapp P-V Réun Cons Perm Int Explor Mer 20:1-228

Hurrell JW, Kushnir Y, Ottersen G, Visbeck M (eds) (2003) The North Atlantic Oscillation: climatic significance and environmental impact. American Geophysical Union, Washington, DC

Huse G, Toresen R (2000) Juvenile herring prey on Barents Sea capelin larvae. Sarsia 85:385-391

ICES (2002a) Report of the Arctic Fisheries Working Group. ICES CM 2002/ACFM:18 International Council for the Exploration of the Sea, Copenhagen (also available at: www.ices.dk/committe/acfm/ wg/afwg/afwg.htm) 
ICES (2002b) Report of the Northern Pelagic and Blue Whiting Fisheries Working Group. ICES CM 2002/ACFM:19 International Council for the Exploration of the Sea, Copenhagen (also available at: www.ices.dk/committe/ acfm/wg/wgnpbw/wgnpbw.htm)

Kendall BE, Prendergast J, Bjornstad ON (1998) The macroecology of population dynamics: taxonomic and biogeographic patterns in population cycles. Ecol Lett 1:160-164

Klyashtorin LB (1998) Long-term climate change and main commercial fish production in the Atlantic and Pacific. Fish Res 37:115-125

Leggett WC, Frank KT, Carscadden JE (1984) Meteorological and hydrographic regulation of year-class strength in capelin (Mallotus villosus). Can J Fish Aquat Sci 41:1193-1201

Lekve K, Stenseth NC, Gjøsæter J, Fromentin JM, Gray JS (1999) Spatio-temporal patterns in diversity of a fish assemblage along the Norwegian Skagerrak coast. Mar Ecol Prog Ser 178:17-27

Lekve K, Stenseth NC, Johansen R, Lingjærde OC, Gjosaeter $\mathrm{J}$ (2003) Richness dependence and climatic forcing as regulating processes of coastal fish-species richness. Ecol Lett $6: 1-12$

Li WKW (2002) Macroecological patterns of phytoplankton in the northwestern North Atlantic Ocean. Nature 419:154-157

Marshall CT, Yaragina NA, Lambert Y, Kjesbu OS (1999) Total lipid energy as a proxy for total egg production by fish stocks. Nature 402:288-290

Mysterud A, Stenseth NC, Yoccoz NG, Ottersen G, Langvatn R (2003) The response of terrestrial ecosystems to climate variability associated with the North Atlantic Oscillation. In: Hurrell JW, Kushnir Y, Ottersen G, Visbeck M (eds) The North Atlantic Oscillation (NAO): climatic significance and environmental impact. American Geophysical Union, Washington, DC, p 235-262

Ottersen G, Loeng H (2000) Covariability in early growth and year-class strength of Barents Sea cod, haddock, and herring: the environmental link. ICES J Mar Sci 57:339-348

Ottersen G, Stenseth NC (2001) Atlantic climate governs oceanographic and ecological variability in the Barents Sea. Limnol Oceanogr 46:1774-1780

Ottersen G, Loeng H, Raknes A (1994) Influence of temperature variability on recruitment of cod in the Barents Sea. ICES Mar Sci Symp 198:471-481

Ottersen G, Adlandsvik B, Loeng H (2000) Predicting the temperature of the Barents Sea. Fish Oceanogr 9:121-135

Ottersen G, Planque B, Belgrano A, Post E, Reid PC, Stenseth NC (2001) Ecological effects of the North Atlantic Oscillation. Oecologia 128:1-14

Ozhigin VK, Luka GI (1985) Some peculiarities of capelin migrations depending on thermal conditions in the Barents Sea. In: Gjosaeter H (ed) The proceedings of the Soviet-Norwegian symposium on the Barents Sea capelin: Bergen, 14-19 August 1984. Institute of Marine Research, Bergen, p 135-147

Pope J, Large P, Jakobsen T (2001) Revisiting the influences of parent stock, temperature, and predation on the recruitment of the Northeast Arctic cod stock, 1930-1990. ICES J Mar Sci 58:967-972

Priestley MB (1981) Spectral analysis of time series. Univariate series. Academic Press, London

Randa K (1982) Recruitment indices for the Arcto-Norwegian Cod for the period 1965-1979 based on the international 0-group fish survey. ICES CM 1982/G:53. International

Editorial responsibility: Andrea Belgrano,

Santa Fe, New Mexico, USA
Council for the Exploration of the Sea, Copenhagen

Randa K (1984) Abundance and distribution of 0-group ArctoNorwegian cod and haddock 1965-1982. In: Godø OR, Tilseth S (eds) Proc Soviet-Norwegian Symp (Leningrad, 25-30 September 1983): Reproduction and recruitment of Arctic Cod. Institute of Marine Research, Bergen, p 192-212

Rodionov SN (1995) Atmospheric teleconnections and coherent fluctuations in recruitment to North Atlantic cod (Gadus morhua) stocks. Can Spec Publ Fish Aquat Sci 121: 45-55

Schwartzlose RA, Alheit J, Bakun A, Baumgartner TR and 17 others (1999) Worldwide large-scale fluctuations of sardine and anchovy populations. S Afr J Mar Sci 21:289-347

Slagstad D, Tande KS (1996) The importance of seasonal vertical migration in across shelf transport of Calanus finmarchicus. Ophelia 44:189-205

Smith KF, Brown JH (2002) Patterns of diversity, depth range and body size among pelagic fishes along a gradient of depth. Global Ecol Biogeogr 11:313-322

Stenseth NC, Mysterud A, Ottersen G, Hurrell JW, Chan KS, Lima M (2002) Ecological effects of climate fluctuations. Science 297:1292-1296

Stenseth NC, Ottersen G, Hurrell JW, Mysterud A, Lima M, Chan KS, Yoccoz NG, Ådlandsvik B (2003) Studying climate effects on ecology through the use of climate indices: the North Atlantic Oscillation, El Niño Southern Oscillation and beyond. Proc R Soc Lond B 270:2087-2096 (also available at: www.pubs.royalsoc.ac.uk/proc_bio/ proc_bio.html)

Stevens GC (1996) Extending Rapoport's rule to Pacific marine fishes. J Biogeogr 23:149-154

Sundby S (2000) Recruitment of Atlantic cod stocks in relation to temperature and advection of copepod populations. Sarsia 85:277-298

Tereshchenko VV (1996) Seasonal and year-to-year variations of temperature and salinity along the Kola meridian transect. ICES CM (C:11):24

Tjelmeland S (1987) The effect of ambient temperature on the spawning migration of capelin. In: Loeng $\mathrm{H}$ (ed) The effect of oceanographic conditions on distribution and population dynamics of commercial fish stocks in the Barents Sea. Proc 3rd Soviet-Norwegian Symp Murmansk, 26 to 28 May 1986. Institute of Marine Research, Bergen, p $225-236$

Toresen R, Østvedt OJ (2000) Variation in the abundance of Norwegian spring-spawning herring (Clupea harengus, Clupeidae) throughout the 20th century and the influence of climatic fluctuations. Fish Fish 1:231-251

Ushakov NG, Prozorkevich DV (2002) The Barents Sea capelin - a review of trophic interrelations and fisheries. ICES J Mar Sci 59:1046-1052

Vilhjalmsson H (2002) Capelin (Mallotus villosus) in the Iceland-East Greenland-Jan Mayen ecosystem. ICES CM 59:870-883

Vinnikov KY, Robock A, Stouffer RJ, Walsh JE and 5 others (1999) Global warming and Northern Hemisphere sea ice extent. Science 286:1934-1937

von Quillfeldt CH, Eliassen JE, Føyn L, Gulliksen B, Lydersen C, Marstrander L (2002) Marine verdier i havområdene rundt Svalbard (Marine values in the oceanic areas around Spitzbergen). Norwegian Polar Institute, Report No. 118, Tromsø

Submitted: April 16, 2003; Accepted: January 27, 2004

Proofs received from author(s): April 20, 2004 